\title{
Reducing a Male Bias in Language? Establishing the Efficiency of Three Different Gender-Fair Language Strategies
}

\author{
Anna Lindqvist ${ }^{1}$ (D) Emma Aurora Renström ${ }^{2} \cdot$ Marie Gustafsson Sendén $^{3}$
}

Published online: 16 October 2018

(C) The Author(s) 2018

\begin{abstract}
Different strategies of gender-fair language have been applied to reduce a male bias, which means the implicit belief that a word describing an undefined person describes a man. This male bias might be caused by the words themselves in terms of generic masculine or masculine forms or by androcentrism (the conflation of men with humanity). In two experiments, we tested how different gender-fair strategies used as labels of an unknown social target (an applicant in a recruitment situation) could eliminate the male bias. The three types of gender-fair strategies tested were: (a) paired forms (he/she), (b) traditional neutral words (e.g., singular they, "the applicant"), or (c) gender-neutral third-person pronouns actively created to challenge the binary gender system (ze, Swedish hen). The two experiments were performed in Swedish with 417 undergraduates in Sweden and in English with 411 U.S. participants recruited online. In Swedish, the third-person gender-neutral pronoun singular (hen) was used. In English, several forms of such gender-neutral pronouns have been suggested (e.g., ze). In both experiments, results indicated that paired forms and actively created gender-neutral pronouns eliminated the male bias, whereas traditional neutral words contained a male bias. Thus, gender-fair language strategies should avoid using traditional words. Consequences of using paired forms and creating new gender-neutral words are discussed. We argue that an actively created gender-neutral pronoun is of highest value because it is more inclusive.
\end{abstract}

Keywords Gender · Gender-studies · Gender-inequality $\cdot$ Language $\&$ languages $\cdot$ Masculinity $\cdot$ Non-sexist language $\cdot$ Sexism in language $\cdot$ Grammatical gender · Gender-fair language $\cdot$ Gender-neutral pronouns $\cdot$ Male bias · Androcentrism $\cdot$ Gender identity

There is a well-documented male bias in language comprehension where supposedly gender-neutral words automatically and unconsciously are associated with men and/or masculinity (Hellinger 2002; Stahlberg et al. 2007), which is one of several examples of how men constitute the norm for humanity (Bailey and LaFrance 2017; Bem 1993; Hegarty and Buechel 2006). It has been suggested that gender-fair

Electronic supplementary material The online version of this article (https://doi.org/10.1007/s11199-018-0974-9) contains supplementary material, which is available to authorized users.

Anna Lindqvist

anna.lindqvist@psy.lu.se

1 Department of Psychology, Lund University, Box 117, 221 00 Lund, Sweden

2 Department of Psychology, Gothenburg University, Gothenburg, Sweden

3 Department of Psychology, Södertörn University, Huddinge, Sweden language reforms, which are linguistic reforms to make language more inclusive, may eliminate this male bias (Douglas and Sutton 2014; Sczesny et al. 2016). However, gender-fair language includes different strategies (Sczesny et al. 2015). To date, few researchers have tested the efficiency of these different strategies in relation to each other regarding the male bias; the few existing studies are also a bit outdated (Gastil 1990; Stahlberg et al. 2001).

In the current experiments, we compare how efficiently different strategies of gender-fair language can eliminate the male bias in language. We specifically test to what extent language reforms using traditional presumed gender-neutral pronouns and nouns, paired pronouns (e.g. he/she), or new actively created pronouns challenging the binary notion of gender can eliminate the male bias. The efficiency of these different forms of gender-fair language is tested in two experiments performed in Swedish and then English. These two languages are similar in having feminine/masculine pronouns (representing she/he) but where the nouns are not conjugated with feminine or masculine gender (Prewitt-Freilino et al. 
2012). Moreover, in both languages there have been attempts to add a third, gender-neutral third-person singular pronoun, which complements the traditional gendered pronouns representing she and he. In Swedish, such a pronounhen - is well-known to the language's users. In English, different forms have been suggested, where $z e$ seems to be the most widespread (cf. Fae 2016).

\section{Male Bias in Language}

A male bias is best described as an implicit assumption that an undefined person is a man (Merritt and Harrison 2006; Merritt and Kok 1995). This association can occur either by words or inflections with explicit grammatical and/or semantical references to men or masculinity. The association could also occur without any linguistic cues, thereby representing an overall androcentric worldview. The term androcentrism recognizes men as more typically representative for human beings (Bem 1993), and it describes the tendency to treat men and masculinity as the norm (Eagly and Kite 1987).

Examples of wordings that include explicit references to men and masculinity include the use of masculine generics (as discussed by Bailey and LaFrance 2017; Merritt and Harrison 2006), For example, he was previously used as a generic pronoun referring to all individuals regardless of gender identity (see Irmen and Roßberg 2004, for a discussion). Other examples of male bias include when professional roles have suffixes that explicitly refers to a masculine gender, such as chairman (McConnell and Fazio 1996) or the Swedish word ombudsman, which refers to a legal representative. Masculine generics are also found in many plural forms of role nouns. In languages where the form of the nouns are inflected based on the gender of the person holding the role (e.g., teacher in German: die Lehrerin/der Lehrer), the masculine form is most often used as the generic plural form (Stahlberg et al. 2001). In some languages, these feminine/ masculine paired forms have been replaced with a neutral form, which most often is the historically masculine form. However, because of its masculine origin, the neutral form still seems to be associated with men and masculinity (e.g., in Norwegian: the word for teacher is now the historically masculine word laerer instead of the paired form laerer/ lcererinne; Gabriel and Gygax 2008).

Moreover, words conjugated with the grammatical gender neuter, which is neither grammatically feminine nor masculine, have been found to contain a male bias. Androcentrism might be the explanation to why neutral words without any grammatical cues in terms of feminine/masculine gender still are associated with men and masculinity (Bailey and LaFrance 2017). Because of this trend, neutral words could contain a male bias even though the word is used in a genderneutral context. A male bias such as this is consequently present even in languages with few linguistic gender markers. For example, the spoken Chinese pronoun tà (meaning she, he or it) most often activates associations of men (Ettner 2002).

The male bias has practical consequences-for example, in recruitment situations. Already in 1973, Bem and Bem showed that women were more motivated to apply for a certain job position when the ad language was actively genderneutral. Since then, attempts to make language more genderfair have been proposed. An overall purpose of gender-fair language is to include everybody, regardless of gender and/ or sexuality (Douglas and Sutton 2014; Sczesny et al. 2016). Gender-fair language in recruitment situations may result in the idea that the gender balance of the advertised position is relatively equal, making not only men motivated to apply for men-dominated positions, such as being a leader of some kind (Horvath and Sczesny 2015). The major strategies of genderfair language reforms are feminization, which aims at making women more visible, and neutralization, which aims at removing gender cues (Sczesny et al. 2015).

\section{Gender-Fair Language Strategies}

In languages where nouns, verbs, and adjectives are conjugated with feminine/masculine gender, feminization is the most common gender-fair language strategy. An example of this strategy is the use of paired forms, both the grammatically feminine and grammatically masculine (Sczesny et al. 2016). The efficiency of such paired forms in eliminating the male bias has been shown in a study by Stahlberg and colleagues (Stahlberg et al. 2001). German speakers who were asked to name their favorite musician/author displayed a male bias, such that mainly men were mentioned when the question was asked using masculine generics (e.g., Musiker). However, this male bias was reduced when paired forms were used (e.g., Musiker/Musikerinnen), such that the examples also included women. The use of paired forms is also a common strategy in languages with feminine/masculine pronouns but without feminine/masculine nouns, such as English and Swedish (Prewitt-Freilino et al. 2012). In both Swedish and English, paired forms of pronouns (he/she) are common. Even though this strategy increases women's visibility, and hence creates more diverse mental images to whom individuals referred, previous research is inconclusive regarding whether paired forms can eliminate the male bias. For example, the use of the Swedish paired pronouns he/she (han/hon) has been shown to still contain a male bias (Wojahn 2015).

Neutralization is used to diminish the salience of femininity or masculinity in language - for example, when the paired feminine/masculine forms are replaced with the historically masculine titles, such as when (for example) author versus authoress are replaced in favor of a neutral use of the suffixless form author (Formanowicz et al. 2013). Neutralization is 
most common in languages where nouns are not conjugated with feminine or masculine gender, such as English and Swedish (Prewitt-Freilino et al. 2012). Another neutralization strategy is to create new words, such as when firefighter and police officer replace the terms fireman and policeman (Sczesny et al. 2016).

Yet another neutralization strategy is the English use of singular they as a gender-neutral generic third-person singular pronoun, mainly used when the gender of someone is unknown (Bodine 1975; Harris et al. 2017; LaScotte 2016; Madson and Hessling 1999; Richards et al. 2016). Singular they, however, can also be used to transcend the binary gender of he/she and hereby refer to an individual with a non-binary gender identity (McGlashan and Fitzpatrick 2018; Zimmer and Carson 2012). Singular they has in some studies been shown to contain a male bias (Bailey and LaFrance 2017; Switzer 1990) even though the results are inconsistent (Gastil 1990; Hyde 1984).

Instead of using existing words as generic, an additional strategy is to create new words, especially gender-neutral third-person singular pronouns, in order to break with the binary gender system (Wayne 2004). Regarding pronouns, such initiatives are found in languages with binary gendered third-person singular pronouns representing she and'he, often in LGBTQ+ communities. For example, in English a wide range of possible gender-neutral third-person singular pronouns has been suggested, such as ze, ve and xe (Grant et al. 2011; Harris et al. 2017; Stotko and Troyer 2007). The probably most well-known pronoun of these is ze (cf. Fae 2016). Whereas singular they has been used both as a generic pronoun and/or when gender is unknown, as well as a referring to individuals with non-binary gender identities, ze is more specifically referring to individuals with non-binary gender identities. However, even though ze might be the most widespread English alternative, the word does still not seem to be known to the broader population of English language users (cf. Harris et al. 2017; McGlashan and Fitzpatrick 2018; Zimmer and Carson 2012). Pronouns derive their meaning from the context (cf. Chung and Pennebaker 2007), indicating that even though the language user is not familiar with the word, the context reveals that the new word has the function of a pronoun. Hence, even though ze is not well-known, a reader may still infer its meaning from the context and understand it.

Similar attempts have been made in many other languages, largely stemming from LGBTQ+ communities. In Swedish, the gender-neutral third-person singular pronoun hen has been intensively debated during the last decade. Swedish hen can be used as a generic pronoun when gender is unknown, irrelevant, or when the target is anonymous or as a pronoun specifically referring to individuals with a non-binary gender identity. This means that hen actually is used both as singular they and as ze.
The implementation of hen was preceded by a heated and polarized debate which started in the 2010s, and many Swedish language users still dislike the word (Bäck et al. 2017a, b; Gustafsson Sendén et al. 2015; Lindqvist et al. 2016). Nonetheless, this public debate led hen to become well-known to the Swedish-speaking population. In fact, as many as 95-99\% were familiar with the word already in 2012-2015 (Gustafsson Sendén et al. 2015). In July 2014, hen was included in The Swedish Academy Glossary (SAOL), constituting the (unofficial) norm of the Swedish language.

\section{Overview of the Present Experiments}

The aim of the present research is to compare how different types of gender-fair language reforms may eliminate the male bias. We contextualize the present research in a recruitment situation, partly because we wanted to have a solid cover story to remove the focus from our aim, but also because this is of particular applied relevance in recruitment situations. Previous research has shown that a male bias during recruitment situations can lead to a preconception that men are the most suitable candidates (Lassonde and Brien 2013), which may lead to higher preferences to hire a man. We performed two experiments, one in Swedish and one in English. We tested the overall strategies of feminization and neutralization using three types of conditions as stimuli: (a) paired forms (he/ she [han/hon] in English and Swedish), (b) neutral traditional nouns and pronouns ("the applicant" in both English and Swedish; NN in Swedish: nomen nescio, which is Latin for "don't know the name"; singular they in English), and (c) new actively created gender-neutral pronouns (Swedish hen and English ze).

The first strategy represents feminization whereas the two latter strategies represent different forms of neutralization. Participants in our two experiments read an anonymous summary of a job candidate applying for a gender-neutral position (in terms of the sector being gender-balanced). We varied how the candidate was being referred to according to the three types of stimuli. Participants were then asked to indicate what gender they believed the job candidate had. In both experiments we used photographs ostensibly showing potential candidates to assess the dependent variable. We define a male bias as the situation when a word activates mental representations of a man to higher frequency than would be expected by chance. If a word does not contain a male bias, participants should choose a photo at random, resulting in a 50/50 distribution of photos of women/men. Hence, for methodological reasons we chose to force participants to associate to binary gender categories.

Following existing literature, our hypothesis is that existing words (nouns or pronouns) used in a new gender-neutral way 
still might contain a male bias and hence be associated with men and masculinity. However, invented new words which lack traditional, androcentric associations to men and masculinity might hence be free from a male bias (cf. Wayne 2004). We proposed three hypotheses: (a) paired forms of he/she contain a male bias (Hypothesis 1), (b) grammatically and thereby supposedly gender-neutral nouns contain a male bias (Hypothesis 2), and (c) actively created gender-neutral pronouns without grammatical cues about gender do not contain a male bias (Prediction 3). Experiment 1 was conducted with Swedish language users whereas Experiment 2 was conducted with U.S. English users.

\section{Experiment 1 - Swedish}

\section{Method}

\section{Participants}

A total of 417 college students $\left(M_{\text {age }}=28.2, S D=8.0\right.$, range 18-68; self-identified as 303 women, 85 men, 24 with nonbinary gender identities, 5 did not indicate gender) completed an online survey. One more person participated in the study, but did not respond to the dependent variable question, and was hence not included in the analyses. The survey was created using the web tool Qualtrics and distributed to a participation pool at the University of Gothenburg in Sweden. This pool mainly consists of current and previous students of different disciplines. The inclusion criterion for participating was being fluent in Swedish.

\section{Design and Procedure}

The design included four between-subjects conditions. Participants read a description of a candidate ostensibly written by a professional recruiter, where the candidate was referred to using; (a) the Swedish actively created genderneutral pronoun hen, (b) the paired pronouns he/she (han/ hon in Swedish), (c) the gender-neutral noun NN (nomen nescio; Latin for "don't know the name"), or (d) the genderneutral neutral noun "the applicant" (den sökande in Swedish). We included two versions of supposedly/ grammatically neutral nouns in order to thoroughly test the male bias.

Participants were informed that the study was about evaluating candidates for a certain job position in a recruitment situation. The questionnaires were introduced with a job advertisement for a gender-neutral position as real-estate agent. This profession has an equal balance between women and men, based on legal gender, according to official Swedish statistics (SCB 2018). Subsequently, participants read the description of a candidate applying for the position, where the candidate was randomly referred to as one of the four conditions. Both the advertisement and the summary were balanced regarding agentic/communal words to avoid any other biases associated with gender. (The stimuli materials can be found in an online supplement.)

The outcome variable in terms of gender-associations of the candidate was measured by asking the participants to select which photo they believed showed the candidate. Four photos (bought from iStock: https://www.istockphoto.com/; the photos can be found in an online supplement) were presented in a randomized order, showing two typically feminine White women and two typically masculine White men. The pictures were chosen based on a pilot study where participants $(n=25)$ rated 10 photos ( 5 women and 5 men). The pilot study validated that the two women were perceived as feminine women, whereas the two men were perceived as masculine men. The women were perceived equally feminine as the men were perceived masculine, which means that that the femininity ratings of the two women were as extreme as were the masculinity ratings of the two men. Moreover, the four chosen photos were rated as plausible candidates for a real estate agent position. This made certain the photos were externally valid and perceived to be realistic. They were also matched on relevant factors such as attractiveness, emotional expression, and age. The chosen pictures were collapsed into a binary gender category. Hence, regardless of which one of the women or men the participants chose, they were coded as responses of either woman or man. Because of face validity we also included other questions as fillers; these were, however, not relevant.

\section{Results and Discussion}

To test the male bias associated with the different conditions, we used Chi-square tests. Hence, we analyzed if the distribution of chosen pictures significantly differed from 50/50, which would imply no male bias because the photos then would have been selected at random.

The wording used in the description of the candidate (hen, he/she, "the applicant", NN) significantly impacted participants' gender associations, $\chi^{2}(3, n=418)=9.88, p=.020$, $\phi_{\mathrm{c}}=.15$. Both the neutral nouns "the applicant" $(67.9 \%$ male), $\chi^{2}(1, n=103)=13.3, p<.001, \phi_{\mathrm{c}}=.36$, and $\mathrm{NN}$ $(66.9 \%$ male $), \chi^{2}(1, n=103)=11.9, p=.001, \phi_{\mathrm{c}}=.34$, contained a male bias. The percentages correspond to the selection of a photo of a man and confirms Hypothesis 2. The paired forms he/she $(50 \%$ male $), \chi^{2}$ he/she $(1, n=106)<001$, $p=1.01, \phi_{\mathrm{c}}=.10$, and the actively created neutral pronoun hen $(56.2 \%$ male $), \chi_{\text {hen }}^{2}(1, n=105)=1.61, p=.205$, $\phi_{\mathrm{c}}=.12$, did not differ from chance levels. In other words, neither hen nor he/she contained a male bias, which confirms Prediction 3 about actively created gender-neutral words but not Hypothesis 1 about paired pronouns. 


\section{Experiment 2 - English}

To further extend the results from the Swedish language in Experiment 1, we tested whether the two gender-fair language strategies would have the same effect in English.

\section{Method}

\section{Participants}

A total of 411 participants $\left(M_{\text {age }}=35.8, S D=11.6\right.$, range $=$ 19-72; self-identified as 145 women, 252 men, 5 transwomen, 4 transmen, 3 with non-binary gender identities, 2 did not indicate gender) completed an online survey experiment. They were recruited through the online participant pool Prolific (Palan and Schitter 2017). Selection criteria for participating were that participants should live in the United States and have English as their first language.

\section{Material and Design}

We used the same design as in Experiment 1 where the participants read about a candidate applying for a job as real estate agent, this time with the four between-subjects conditions: (a) actively created, gender-neutral pronoun ze, (b) the paired pronouns he/she, (c) gender-neutral (singular) they, or (d) gender-neutral "the applicant." The outcome variable of this experiment was the same as in Experiment 1, where the participants selected which one of (the same) four photos they associated with the candidate (see the online supplement). Following the procedure of Experiment 1, the responses were first collapsed across gender of the portrayed person such that that choosing any of the two women was treated as a gender association to a woman, whereas choosing any of the two men was treated as a gender association to a man.

As mentioned, Swedish is the only language so far where an actively created gender-neutral third person pronoun singular is well-known to a broad range of the language users. To examine if English counterparts (like ze) were known to our participants, we also added a question about familiarity of English gender-neutral pronouns. At the end of the questionnaire, after having read about the job candidate and indicated their gender, participants were asked to indicate with which of the following actively invented gender-neutral third-person singular pronouns they were familiar: ze, ve, ne, xe. We also asked about their familiarity with the singular they. For each of the five pronouns, participants could choose any of the alternatives "not familiar", "familiar, have not used," and "familiar, have used". Participants could also indicate any other gender-neutral third-person singular pronouns with which they were familiar.

\section{Results and Discussion}

As in Experiment 1, we assessed male bias using Chi-square tests to analyze if the distribution of gender associations differed from chance levels. The wording used in the description of the candidate (ze, he/she, singular they, "the applicant") significantly impacted participants' gender associations, $\chi^{2}(3, n=411)=13.23, p=.004, \phi_{c}=.18$. The gender-neutral noun "the applicant" was again mainly thought to be a man $(62.1 \%$ male $), \chi^{2}(3, n=103)=6.07, p=.014, \phi_{\mathrm{c}}=.24$, which confirms Hypothesis 2. The same result was obtained for the gender-neutral (singular) they, where $68.4 \%$ of the participants associated they with a masculine gender, $\chi^{2}(3, n=$ $95)=12.9, p<.001, \phi_{\mathrm{c}}=.37$, which also confirms Hypothesis 2. However, following the Swedish results, $44.0 \%$ associated the paired he/she with a masculine gender, a result which did not significantly differ from the 50/50 distribution, $\chi^{2}(1, n=116)=1.69, p=.194, \phi_{c}=.12$, failing to confirm Hypothesis 1. A total of $49.5 \%$ of the participants in the actively created, gender-neutral ze condition selected a photo of a man, not differing significantly from a 50/50 distribution, $\chi^{2}(1, n=97)=.01, p=.919, \phi_{\mathrm{c}}=.01$, thus conforming with Prediction 3 . The results corroborate those from Experiment 1 in that both the paired form he/she and the new created gender-neutral pronoun ze did not show a male bias.

Among the participants reading about ze, there was no significant difference in gender-association of the candidate, depending on if the participants were familiar with the word ze or not. Those who responded that they were familiar with the word but never used it $(n=31)$ chose a man $58 \%$ of the time whereas those who were not familiar with the word $(n=48)$ selected the man $62.5 \%$ of the time - a significant difference, $\chi^{2}(1, N=79)=3.76, p=.153, \phi_{\mathrm{c}}=.22$. Moreover, both percentages did not differ significantly from $50 / 50$ chance: $\chi 2_{\text {familiar }}(1, N=48)=3.00, p=.083, \phi_{\mathrm{c}}=.25 ; \chi 2_{\text {unfamiliar }}(1$, $N=31)=.29, p=.590, \phi_{\mathrm{c}}=.10$. These latter tests suggest that an actively created gender-neutral pronoun can eliminate the male bias, regardless of whether the reader is familiar with the word or not.

Additionally, we tested whether participants were familiar with different gender-neutral third-person singular pronouns. Table 1 shows the familiarity of the pronouns, a total of 326 participants $(79.3 \%)$ of the participants responded to this question. As can be seen in the table, almost all of the participants who responded to this question were familiar with singular they, however, fewer were familiar with the other pronouns ranging from ze, xe, ve, ne. This pattern supports our contention that the singular they is not in the same category as the newly created gender-neutral alternatives, instead constituting a familiar word with a simple different use (i.e., singular rather than the conventional plural). 
Table 1 U.S. participants familiarity with presumably gender-neutral English pronouns

\begin{tabular}{llll}
\hline Pronoun & $\begin{array}{l}\text { Familiar, have used } \\
n(\%)\end{array}$ & $\begin{array}{l}\text { Familiar, have not used } \\
n(\%)\end{array}$ & $\begin{array}{l}\text { Total familiarity } \\
n(\%)\end{array}$ \\
\hline (singular) they & $282(86.5 \%)$ & $33(10.1 \%)$ & $315(96.6 \%)$ \\
ze & $43(13.3 \%)$ & $84(25.9 \%)$ & $127(39.2 \%)$ \\
xe & $43(13.3 \%)$ & $63(19.5 \%)$ & $106(32.8 \%)$ \\
ve & $37(11.5 \%)$ & $40(12.4 \%)$ & $77(23.9 \%)$ \\
ne & $34(10.4 \%)$ & $43(13.2 \%)$ & $77(23.9 \%)$ \\
\hline
\end{tabular}

All percentages are based on the 326 participants who responded to this question
Participants also reported the other gender-neutral thirdperson pronouns with which they were familiar: ey (4), it (4), s/he (3), zhe (2), shim (1), zim (1) and even hen (1). Compared to the process when hen was implemented in the Swedish language, not many Swedes were familiar with the pronoun when the heated debate about the word sparked off in 2010 (see Bäck et al. 2015). Already 3 years later, in 2013, more than $95 \%$ of the Swedish participants were familiar with the word (Gustafsson Sendén et al. 2015). This implementation is partly a result of active feminist language planning (cf. Milles 2011) which could be used to make, for example, ze a common and well-known word in the English vocabulary.

\section{General Discussion}

The aim of the present research was to evaluate different gender-fair language strategies with regard to eliminating the male bias in language. In two experiments performed in English and Swedish, we showed that both a feminization strategy in terms of the paired pronouns he/she and a neutralization strategy in terms of the newly created gender-neutral English pronoun ze or Swedish pronoun hen seemed to successfully eliminate the male bias. However, the neutralization strategies in terms of existing, presumably gender-neutral nouns such as "the applicant" in Swedish and English or $\mathrm{NN}$ in Swedish did not eliminate the male bias; neither did the English singular they, which confirms the suggestion to actively invent new words in order to avoid a male bias (cf. Wayne 2004).

Hence, both of the actively created pronouns ze and hen could eliminate a male bias. However, this was not the case with the gender-neutral pronoun singular they. At this point, we can only speculate about the causes of this difference in male bias of the different neutral pronouns. One hypothesis is that since singular they is a traditional pronoun with a long history-even Shakespeare used they as a generic thirdperson pronoun singular (Zimmer and Carson 2012) — so it might still elicit heuristics of androcentrism. In other words, one speculation is that traditional words may evoke the implicit view that the undefined person is a man. As a contrast, both actively created gender-neutral pronouns ze and hen challenge the binary gender system, which may be effective when eliminating the male bias. Perhaps new constructions require people to actively think, which might eliminate the gender bias. However, more research is needed to draw such conclusions.

Regarding the neutral nouns used as stimuli in these experiments ("the applicant" in both languages; NN in Swedish), they seem to contain a male bias both in English and Swedish. A common argument against the use of hen in Sweden is that there are other words to use if one wants to express gender-neutrality (Vergoossen et al. 2016). The current research shows that this is not the case; other presumably neutral words contain a male bias and can accordingly not be seen or treated as truly neutral. These findings are in line with previous research which shows that neutral, albeit masculine generic, wordings contain a male bias (Gabriel and Gygax 2008). We extend on these findings and show that even when there is no grammatical reference to gender, neutral nouns can still be associated with men. An interesting venue to pursue would be to investigate if other presumably neutral wordings contain a male bias as well, for instance, wordings such as parents instead of mums and dads and child instead of daughter or son.

Even though the paired pronoun form he/she did not evoke a male bias, it should be noted that this wording still refers to gender as a binary category consisting of women and men (cf. cisgenderism; Ansara and Hegarty 2014). Because there are many other gender identities, between and/or outside the traditional notion of gender as a binary category, other wordings than he/she should be considered (see e.g., Harris et al. 2017).

An interesting finding is that even though most participants were not familiar with the pronoun ze, they still seemed to be able to understand it. Because pronouns derive their meaning from the context (cf. Chung and Pennebaker 2007), it seems that people are able to grasp its meaning without being familiar with it. In comparison, most Swedish language users are familiar with the word hen and its use (Gustafsson Sendén et al. 2015).

\section{Practice Implications}

Feminists often argue that language can be used to reduce stereotypes and implicit discrimination (Hellinger 2002), and 
gender-fair language has already been suggested to have an applied impact in, for example, recruitment situations (Bem and Bem 1973; Horvath and Sczesny 2015). Our research adds to the current research on gender-fair language by establishing how the feminization and neutralization strategies using both traditional and new words may eliminate the male bias in language comprehension. Our results show that some traditional "neutral" words are not perceived as gender-neutral, thereby calling for the implementation of words that do not activate mental representations of an androcentric world view.

\section{Limitations and Future Research Directions}

Some limitations are worth noting in relation to the present research. First, we forced participants to make binary gender associations. This was a deliberate choice because we wanted specifically to test the associations to a man - not how gender associations in general were elicited by different wordings. However, future research should include individuals with non-normative gender expressions as response options, especially when it comes to the non-male-biased wordings (he/she, hen and ze). This strategy will reveal how these wordings actually are processed in terms of gender associations and categorizations - as generic pronouns to be used when gender is unknown but still implying one of the common genders of a normative woman/man (i.e., a binary bias) or as describing an individual of any gender including non-normative and/or genderqueer expressions.

A note on our samples is also worth pointing out. In the first experiment with Swedish participants, we used a pool consisting of students (and former students) from a Swedish university located in Sweden's second largest city. We know from previous research that both higher education and living in larger cities are related to more positive attitudes to genderfair language (Bäck et al. 2017a, b). Moreover, even though Prolific does have a wider range of individuals in their online panel, it is still biased toward younger, more educated, and more liberal individuals (Bäck et al. 2017a, b). Hence, the results may be different using other samples. Nonetheless, because our research did not investigate attitudes but only gender categorization, which should be unaffected by attitudinal position, we believe that this is less of a problem. Also regarding the gender composition of the samples, there were more women in Experiment 1 and more men in Experiment 2. The results were the same, suggesting that gender of participant did not matter. However, effects of participants' gender were not explicitly tested.

\section{Conclusion}

The already identified male bias in language comprehension was found in our results, where the "neutral" individual continued to be associated with a male/masculine gender, even though genderless neutral words earlier have been suggested as alternatives to masculine generics (Madson and Hessling 1999). Nonetheless, the use of the paired pronouns he/she, as well as the use of an actively invented genderneutral pronoun both in English (ze) and Swedish (hen) seemed to eliminate the male bias. This finding should be of particular interest to the field. Because earlier research on the neutralization strategy still has identified a male bias, it is of great importance to show that a newly created gender-neutral third-person singular pronoun seems to diminish the male bias. However, because the paired form he/she implies a binary gender, other forms such as actively invented gender-neutral pronouns should be considered.

Funding The present research was funded by the Swedish Research Council for Health, Working Life and Welfare (grant 2017-00418), the Swedish Research Council (grant 2014-1150) and the Swedish Foundation for Humanities and Social Sciences (grant P16-0058:1).

\section{Compliance with Ethical Standards}

Conflicts of Interest This work was supported by the Swedish Research Council (grant 2014-1150), the Swedish Research Council for Health, Working Life and Welfare (grant 2017-00414) and the Swedish Foundation for Humanities and Social Sciences (grant P16-0058:1). The authors declare that they have no conflict of interest.

Research Involving Human Participants and/or Animals All procedures performed in studies involving human participants were in accordance with the ethical standards. No animals were involved in the research.

Informed Consent Informed consent was obtained from all individual participants included in the study.

Open Access This article is distributed under the terms of the Creative Commons Attribution 4.0 International License (http:// creativecommons.org/licenses/by/4.0/), which permits unrestricted use, distribution, and reproduction in any medium, provided you give appropriate credit to the original author(s) and the source, provide a link to the Creative Commons license, and indicate if changes were made.

\section{References}

Ansara, Y. G., \& Hegarty, P. (2014). Methodologies of misgendering: Recommendations for reducing cisgenderism in psychological research. Feminism \& Psychology, 24(2), 259-270. https://doi.org/10. $1177 / 0959353514526217$.

Bäck, E. A., Lindqvist, A., \& Gustafsson-Sendén, M. (2015). Hen can do it: Effects of using a gender neutral pronoun in a recruitment situation. In J. Magnusson, K. Milles, \& Z. Nikolaidou (Eds.), Könskonstruktioner och Språkförändringar: En rapport från den Åttonde Nordiska Konferensen om Språk och Kön [gender constructions and language changes: A report from the 8th Nordic conference on gender and language] (pp. 71-91). Sweden: Södertörn University.

Bäck, H., Carroll, R., Hansen, M., \& Bäck, E. A. (2017a). Chivalry or chauvinism? The impact of benevolent and hostile sexism in the 
2016 US presidential election. Presented at the Nordic Political Science Association, Odense.

Bäck, E. A., Lindqvist, A., \& Gustafsson Sendén, M. (2017b). Hen: Bakgrund, attityder och användande [Hen: Background, attitudes and use]. Psykologiska rapporter från Lund, 8(1), 1-34. Retreived from https://www.psy.lu.se/sites/psy.lu.se/files/plr_1801.pdf.

Bailey, A. H., \& LaFrance, M. (2017). Who counts as human? Antecedents to androcentric behavior. Sex Roles, 76(11-12), 682 693. https://doi.org/10.1007/s11199-016-0648-4.

Bem, S. L. (1993). The lenses of gender: Transforming the debate on sexual inequality. New Haven: Yale University.

Bem, S. L., \& Bem, D. J. (1973). Does sex-biased job advertising "aid and abet" sex discrimination? Journal of Applied Social Psychology, 3, 6-18. https://doi.org/10.1111/j.1559-1816.1973.tb01290.x.

Bodine, A. (1975). Androcentrism in prescriptive grammar: Singular 'they', sex-indefinite 'he', and 'he or she'. Language in Society, 4(2), 129-146. https://doi.org/10.1017/S0047404500004607.

Chung, C., \& Pennebaker, J. W. (2007). The psychological functions of function words. Social Communication, 1, 343-359. https://doi.org/ 10.4324/9780203837702.

Douglas, K. M., \& Sutton, R. M. (2014). "a giant leap for mankind" but what about women? The role of system-justifying ideologies in predicting attitudes toward sexist language. Journal of Language and Social Psychology, 33(6), 667-680. https://doi.org/10.1177/ $0261927 X 14538638$.

Eagly, A. H., \& Kite, M. E. (1987). Are stereotypes of nationalities applied to both women and men? Journal of Personality and Social Psychology, 53(3), 451-462. https://doi.org/10.1037/0022-3514.53.3.451.

Ettner, C. (2002). In Chinese, men and women are equal - or - women and men are equal? In M. Hellinger \& H. Bußmann (Eds.), Gender across languages: The linguistic representation of women and men (pp. 29-55). Netherlands: John Benjamins Publishing Company

Fae, J. (2016). Non-gendered pronouns are progress for trans and nontrans people alike. The Guardian. Retrieved from https://www. theguardian.com/commentisfree/2016/dec/14/non-genderedpronouns-trans-people-he-she-ze.

Formanowicz, M., Bedynska, S., Cisłak, A., Braun, F., \& Sczesny, S. (2013). Side effects of gender-fair language: How feminine job titles influence the evaluation of female applicants. European Journal of Social Psychology, 43(1), 62-71. https://doi.org/10.1002/ejsp.1924.

Gabriel, U., \& Gygax, P. (2008). Can societal language amendments change gender representation? The case of Norway. Scandinavian Journal of Psychology, 49, 451-457. https://doi.org/10.1111/j.14679450.2008.00650.x.

Gastil, J. (1990). Generic pronouns and sexist language: The oxymoronic character of masculine generics. Sex Roles, 23(11-12), 629-643. https://doi.org/10.1007/BF00289252.

Grant, J. A., Mottet, L. A., Tanis, J., Harrison, J., Herman, J. L., \& Kiesling, M. (2011). Injustice at every turn. A report of the National Transgender Discrimination Survey. Retrieved from http://transequality.org/sites/default/files/docs/resources/NTDS Exec_Summary.pdf.

Gustafsson Sendén, M., Bäck, E. A., \& Lindqvist, A. (2015). Introducing a gender-neutral pronoun in a natural gender language: The influence of time on attitudes and behavior. Frontiers in Psychology, 6, article 893. https://doi.org/10.3389/fpsyg.2015.00893.

Harris, C. A., Biencowe, N., \& Telem, D. A. (2017). What's in a pronoun? Why gender-fair language matters. Annals of Surgery, 266(6), 932-933. https://doi.org/10.1097/SLA.0000000000002505.

Hegarty, P., \& Buechel, C. (2006). Androcentric reporting of gender differences in APA journals: 1965-2004. Review of General Psychology, 10(4), 377-389. https://doi.org/10.1037/1089-2680. 10.4.377.

Hellinger, M. (2002). The linguistic representation of women and men. In M. Hellinger \& H. Bußmann (Eds.), Gender across languages: The linguistic representation of women and men (Vol. 2, pp. 1-25). Amsterdam: John Benjamins Publishing Company.

Horvath, L. K., \& Sczesny, S. (2015). Reducing women's lack of fit with leadership positions? Effects of the wording of job advertisements. European Journal of Work and Organizational Psychology, 25(2), 316-328. https://doi.org/10.1080/1359432X.2015.1067611.

Hyde, J. S. (1984). Children's understanding of sexist language. Developmental Psychology, 20, 697-706. https://doi.org/10.1037/ 0012-1649.20.4.697.

Irmen, L., \& Roßberg, N. (2004). Gender markedness of language: The impact of grammatical and nonlinguistic information on the mental representation of person information. Journal of Language and Social Psychology, 23, 272-307. https://doi.org/10.1177/ $0261927 X 04266810$.

LaScotte, D. K. (2016). Singular they: An empirical study of generic pronoun use. American Speech, 91(1), 62-80. https://doi.org/10. 1215/00031283-3509469.

Lassonde, K. A., \& Brien, J. O. (2013). Occupational stereotypes: Activation of male bias in a gender-neutral world. Journal of Applied Social Psychology, 43, 387-396. https://doi.org/10.1111/j. 1559-1816.2013.01008.x.

Lindqvist, A., Gustafsson Sendén, M., \& Bäck, E. A. (2016). Vem tycker om hen? [Who likes hen?] Språk och Stil, 26, 101-129. Retreived from http://uu.diva-portal.org/smash/get/diva2:1071277/ FULLTEXT01.pdf.

Madson, L., \& Hessling, R. M. (1999). Does alternating between masculine and feminine pronouns eliminate perceived Ggender bias in text? Sex Roles, 41(7/8), 559-575. https://doi.org/10.1023/A: 1018895321444

McConnell, A. R., \& Fazio, R. H. (1996). Women as men and people: Effects of gender-marked language. Personality and Social Psychology Bulletin, 22(10), 1004-1013. https://doi.org/10.1177/ 01461672962210003.

McGlashan, H., \& Fitzpatrick, K. (2018). 'I use any pronouns, and I'm questioning everything else': Transgender youth and the issue of gender pronouns. Sex Education, 18(3), 239-252. https://doi.org/ 10.1080/14681811.2017.1419949.

Merritt, R. D., \& Harrison, T. W. (2006). Gender and ethnicity attributions to a gender- and ethnicity-unspecified individual: Is there a people $=$ white male bias? Sex Roles, 54(11-12), 787-797. https://doi.org/10. 1007/s11199-006-9046-7.

Merritt, R. D., \& Kok, C. J. (1995). Attribution of gender to a genderunspecified individual: An evaluation of the people = male hypothesis. Sex Roles, 33, 145-157. https://doi.org/10.1007/s11199006-9046-7.

Milles, K. (2011). Feminist language planning in Sweden. Current Issues in Language Planning, 12, 21-33. https://doi.org/10.1080/ 14664208.2011.541388.

Palan, S., \& Schitter, C. (2017). Prolific.Ac - A subject pool for online experiments. Journal of Behavioral and Experimental Finance, 17 , 22-27. https://doi.org/10.1016/j.jbef.2017.12.004.

Prewitt-Freilino, J. L., Caswell, T. A., \& Laakso, E. K. (2012). The gendering of language: A comparison of gender equality in countries with gendered, natural gender, and genderless languages. Sex Roles, 66(3), 286-281. https://doi.org/10.1007/s11199-011-0083-5.

Richards, C., Bouman, W. P., Seal, L., Barker, M. J., Nieder, T. O., \& T'sjoen, G. (2016). Non-binary or genderqueer genders. International Review of Psychiatry, 28(1), 95-102. https://doi.org/ 10.3109/09540261.2015.1106446.

SCB, Statistics Sweden. (2018). Women and men in Sweden - Facts and figures 2018. Stockholm: Statistics Sweden. Retreived from http:// www.scb.se/en/finding-statistics/statistics-by-subject-area/livingconditions/gender-statistics/gender-statistics/pong/publications/ women-and-men-in-sweden.-facts-and-figures-2018/.

Sczesny, S., Moser, F., \& Wood, W. (2015). Beyond sexist beliefs: How do people decide to use gender-inclusive language? Personality and 
Social Psychology Bulletin, 41(7), 943-954. https://doi.org/10. 1177/0146167215585727.

Sczesny, S., Formanowicz, M., \& Moser, F. (2016). Can gender-fair language reduce gender stereotyping and discrimination? Frontiers in Psychology, 7, article 25. https://doi.org/10.3389/ fpsyg.2016.00025.

Stahlberg, D., Sczesny, S., \& Braun, F. (2001). Name your favorite musician: Effects of masculine generics and of their alternatives in German. Journal of Language and Social Psychology, 20(4), 464 469. https://doi.org/10.1177/0261927X01020004004.

Stahlberg, D., Braun, F., Irmen, L., \& Sczesny, S. (2007). Representation of the sexes in language. In K. Fiedler (Ed.), Social communication (pp. 163-187). New York: Psychology Press.

Stotko, E. M., \& Troyer, M. (2007). A new gender-neutral pronoun in Baltimore, Maryland: A preliminary study. American Speech, 82(3), 262-279. https://doi.org/10.1215/00031283-2007-012.
Switzer, J. Y. (1990). The impact of generic word choices: An empirical investigation of age- and sex-related differences. Sex Roles, 22(172), 69-81. https://doi.org/10.1007/BF00288155.

Vergoossen, H., Bäck, E. A., Lindqvist, A., \& Gustafsson Sendén, M. (2016, May). Contemporary arguments against gender-neutral language. Presented at the Association for Psychological Science (APS) 28th Annual Convention, Chicago.

Wayne, L. D. (2004). Neutral pronouns: A modest proposal whose time has come. Canadian Women Studies, 24(2/3), 85-92. Retreived from https://cws.journals.yorku.ca/index.php/cws/article/download/ $6122 / 5310$.

Wojahn, D. (2015). Språkaktivism : Diskussioner om feministiska språkförändringar i Sverige från 1960-talet till 2015 [Language activism: Discussions about feminist language changes in Sweden from the 1960s to 2015]. Location: Uppsala University, Department of Nordic languages, Uppsala, Sweden.

Zimmer, B., \& Carson, C. E. (2012). Among the new words. American Speech, 87(4), 491-510. https://doi.org/10.1215/00031283-1587259. 